\title{
Skin thickness score as a surrogate marker of organ involvements in systemic sclerosis: a retrospective observational study
}

\author{
Kazuki M. Matsuda', Ayumi Yoshizaki", Ai Kuzumi', Takemichi Fukasawa', Satoshi Ebata', Shunsuke Miura', \\ Tetsuo Toyama ${ }^{1}$, Asako Yoshizaki ${ }^{1}$, Hayakazu Sumida', Yoshihide Asano ${ }^{1}$, Koji Oba $^{2}$ and Shinichi Sato ${ }^{1}$
}

\begin{abstract}
Background: Previous studies have shown the relationship between higher skin thickness score and the existence of organ involvements in systemic sclerosis (SSc). Here, we firstly investigated the correlation between skin thickness score and quantitative measurements of each organ involvement in Japanese patients with SSc.

Methods: All Japanese SSc patients hospitalized to our clinic for initial evaluation of SSc were selected. Skin thickness was evaluated by modified Rodnan total skin thickness score (mRSS). Relationship between mRSS and prevalence or incidence of organ involvements was examined by logistic analyses. Correlation between mRSS and quantitative measurements of organ involvements was examined by correlation analyses and regression analyses.

Results: We recruited 198 patients into our study. The mean disease duration was 7.3 years with the mean followup duration of 3.2 years. Multivariate logistic regression analyses revealed that higher mRSS is related to higher prevalence of interstitial lung disease $(P<0.05)$, restrictive impairment $(P<0.01)$, and diffusion impairment $(P<0.05)$ of the lung. Correlation analyses revealed mRSS negatively correlates with forced vital capacity $(P<0.001)$ and diffusing capacity $(P<0.001)$ of the lung. Correlation between longitudinal change of mRSS and that of forced vital capacity $(P<0.05)$ or diffusing capacity $(P<0.001)$ of the lung was also demonstrated.
\end{abstract}

Conclusions: Skin thickness score significantly correlates with quantitative measurements of lung involvement in Japanese patients with SSC.

Keywords: Systemic sclerosis, Modified Rodnan total skin thickness score, Interstitial lung disease, Regression analysis

\section{Background}

Systemic sclerosis (SSc) is a connective tissue disease characterized by fibrosis, vascular injury, and immunological abnormality across multiple organs [1]. Variable symptoms of SSc are the reflection of each organ involvement by different aspects of the pathology, which makes it difficult to grasp the whole picture of the disease. For example, fibrosis of the dermis causes skin sclerosis [2], while alveolar fibrosis causes systemic sclerosis-related interstitial lung disease (SSc-ILD) [3]. In addition, vascular injury in the extremities causes digital

\footnotetext{
* Correspondence: yoshizakiay-der@h.u-tokyo.ac.jp

'Department of Dermatology, The University of Tokyo Graduate School of Medicine, 7-3-1, Hongo, Bunkyo-ku, Tokyo 1138655, Japan

Full list of author information is available at the end of the article
}

ulcer [4], renal involvement triggers SSc renal crisis (SRC) [5], and impairment of the pulmonary arteries causes pulmonary hypertension [6]. The reflection of immunological abnormality is a variety of autoantibodies detected from the sera of SSc patients [7, 8].

Effective treatment differs by each organ involvement, which requires clinicians to combine multiple therapeutic modalities to treat SSc patients. Some medications have pivotal effect on each organ involvement, making the treatment further difficult. For instance, systemic corticosteroids are used in treating skin fibrosis and SSc-ILD [9, 10], while high-dose corticosteroids are known as a risk factor of SRC development $[11,12]$. Calcium channel blockers are sometimes used for treating Raynaud's phenomenon in SSc patients [13], but they

(C) The Author(s). 2019 Open Access This article is distributed under the terms of the Creative Commons Attribution 4.0 International License (http://creativecommons.org/licenses/by/4.0/), which permits unrestricted use, distribution, and 
worsen the symptoms of gastroesophageal reflux disease (GERD) [14]. To optimize the combination of such multiple therapeutic modalities, evaluation of severity and disease activity for SSc patients should be multidimensional. Skin thickness is one of such measurements that have long time been used and evaluated as a barometer that mainly reflects the aspect of fibrosis. It has been revealed that tighter skin is a predictive factor of death [15], heart involvement [16], muscle involvement [17], and development of SRC $[18,19]$. In addition, higher skin thickness score is related to severer function disability of SSc patients measured by health assessment questionnaire disability index [20,21]. It has also been reported that rapid increase in skin thickness score is a predictor of higher incidence of early death and SRC [22].

Modified Rodnan total skin thickness score (mRSS) is one of the established methods to examine the skin thickness of SSc patients. It is a semiquantitative, noninvasive, and rapid method to measure the skin thickness with high reproducibility [18], which makes it widely used both in clinical trials and real clinical practice [23]. Previous studies have investigated the relationship between incidence of disease-related events or presence of organ involvement and skin thickness that was quantitatively evaluated [15-19]. However, almost all of them targeted Caucasians, Hispanics, or African American patients.

Herein, we investigated the correlation between mRSS and quantitative measurements of organ involvement by retrospective observation of Japanese SSc cohort. Our goal is to evaluate the utility of mRSS as a quantitative barometer of other organ involvement in SSc patients.

\section{Methods}

\section{Subject patients}

We included all the patients with SSc hospitalized to our clinic since May 2011 until April 2018. All the new patients arrived at our clinic receives initial evaluation for SSc, including physical examinations, laboratory tests, high-resolution computed tomography (HRCT) scanning of the lung, pulmonary function tests, transthoracic echocardiography, and gastrointestinal endoscopy. Only Japanese patients hospitalized for initial evaluation of SSc were recruited into the present study. We excluded patients who did not meet the classification criteria for SSc established by American College of Rheumatology and European League Against Rheumatism in 2013 (ACR/EULAR criteria 2013) [24]. This study was approved by the ethics committee at The University of Tokyo Hospital.

\section{Data collection}

We retrospectively reviewed the electronic medical records. The patients' demographic information, laboratory results, and examination findings were obtained at the time closest to the first admission to our clinic. The collected demographic information included age, sex, disease duration, follow-up duration, and medication regimen. The laboratory results included autoantibody profiles, blood cell counts, C-reactive protein (CRP) levels, and erythrocyte sedimentation rates (ESRs).

Longitudinal data of mRSS and the result of pulmonary function test were collected from the most recent time when these examinations were performed at the same time.

\section{Qualitative evaluation of organ involvements}

Systolic dysfunction of the heart was defined as left ventricle ejection fraction (LVEF) $<50 \%$. Diastolic dysfunction of the heart was defined as ratio between early mitral inflow velocity and mitral annular early diastolic velocity $\left(E / e^{\prime}\right)>15$. Pulmonary hypertension was defined as mean pulmonary artery pressure $>25 \mathrm{mmHg}$ on right heart catheterization. Presence of SSc-ILD was determined upon HRCT readings. Restrictive impairment of the lung was defined as the percentage of predicted forced vital capacity $(\% \mathrm{FVC})<80 \%$. Patients with the ratio of forced expiratory volume in $1 \mathrm{~s}$ to forced vital capacity $(\mathrm{FEV} 1 \%)<70 \%$ were excluded to rule out the obstructive components of the lung. Diffusion impairment of the lung was defined as the percentage of diffusing capacity for carbon monoxide (\%DLco) $<70 \%$. Classification of GERD findings from upper gastrointestinal endoscopy was performed by gastroenterologists, and reflux esophagitis was defined as Grade $\mathrm{M}$ or more on Los Angeles classification of esophagus [25]. Myositis was defined as elevation of serum CK twofold higher than the upper normal limit.

The reviewed disease-related events contained death, SRC, ileus, and heart failure that were observed since the primary evaluation until the most recent arrival to our clinic. Occurrence of SRC, ileus, and heart failure was determined upon clinical diagnosis.

\section{Quantitative or categorical evaluation of organ involvements}

The degree of skin sclerosis was scored on mRSS by 6 dermatologists at The University of Tokyo Scleroderma Center, all of whom had been trained by repeated teaching method previously described [26]. The evaluation value of lung involvement included serum levels of Krebs von den Lungen-6 (KL-6) and surfactant protein$\mathrm{D}$ (SP-D) levels, and pulmonary function parameters including \%FVC and \%DLco. Quantitative evaluation of heart involvement encompassed serum level of brain natriuretic peptide (BNP) and the results of echocardiography including LVEF, E/e, and right ventricle systolic pressure (RVSP). Renal involvement was described by estimated glomerular filtration rate (eGFR). Severity of 
GERD on upper gastrointestinal endoscopy was categorically evaluated by Los Angeles classification of esophagus. Quantitative measurement of musculoskeletal system included the serum level of creatinine kinase (CK).

\section{Statistical analyses}

Univariate analysis was performed by single logistic analysis for categorical variables and single regression analysis for continuous variables. Correlation analysis was also performed between some continuous variables to estimate Pearson's correlation coefficient. Multivariate analysis was performed by multiple logistic analysis for categorical variables and multiple regression analysis for continuous variables. Explanatory variables in multivariate analysis were age, sex, disease duration, and mRSS. In sensitivity analyses, the following explanatory variables were added: baseline presence of pulmonary hypertension, the use of corticosteroids or immunosuppressants, the use of vasoactive agents (endothelin receptor antagonists, phosphodiesterase 5 inhibitors, beraprost, sarpogrelate hydrochloride, limaprost alfadex, and angiotensin-converting enzyme inhibitors), and the history of smoking. All the analyses were performed using Stata/IC 15 (StataCorp LLC, TX, USA).

\section{Results}

\section{Demographics of the subject patients}

In total, there were 1101 patients with SSc hospitalized to our clinic during the study period. We selected 228 patients who were hospitalized for initial evaluation of SSc and excluded 28 patients because they did not meet ACR/EULAR criteria 2013. Two patients were excluded because they were from Taiwan and the Philippines. As a result, 198 Japanese patients were recruited into our study (Fig. 1). The background features of the participants are summarized in Table 1. Their mean age was 55.4 years old (standard deviation $[\mathrm{SD}]=15.5$ ) with the number of female patients of 177 (89.4\%). The mean disease duration was 7.3 years $(\mathrm{SD}=8.8)$ with the mean follow-up duration of 3.2 years $(\mathrm{SD}=2.3)$. The proportion of patients with history of smoking was $21.9 \%$. Almost half of the patients $(46.8 \%)$ had diffuse cutaneous SSc. The frequency of specific autoantibody positivity in the sera of the patients was as follows: antitopoisomerase (topo) I antibody (Ab) in 78 patients (39.4\%), anti-centromere $\mathrm{Ab}$ in 64 patients (32.3\%), antiRNA polymerase III Ab in 21 patients (10.6\%), and antiU1RNP Ab in 22 patients (11.1\%). Corticosteroids or immunosuppressants had already been introduced in 50 patients (25.3\%), and vasoactive agents had been administered to 74 patients $(37.4 \%)$.

\section{Incidence and prevalence of organ involvements}

The number of patients with each organ involvement was as follows: interstitial lung diseases in 87 patients (44.4\%), restrictive impairment of the lung in 36 patients $(18.3 \%)$, diffusion impairment of the lung in 33 patients (17.3\%), diastolic dysfunction of the heart in 10 patients $(6.7 \%)$, pulmonary hypertension in 5 patients $(2.5 \%)$, heart failure in 3 patients $(1.5 \%)$, SRC in 6 patients $(3.0 \%)$, reflux esophagitis in 78 patients (43.6\%), ileus in 6 patients $(3.0 \%)$, and myositis in 7 patients $(3.6 \%)$. There were no patients with systolic dysfunction of the heart.

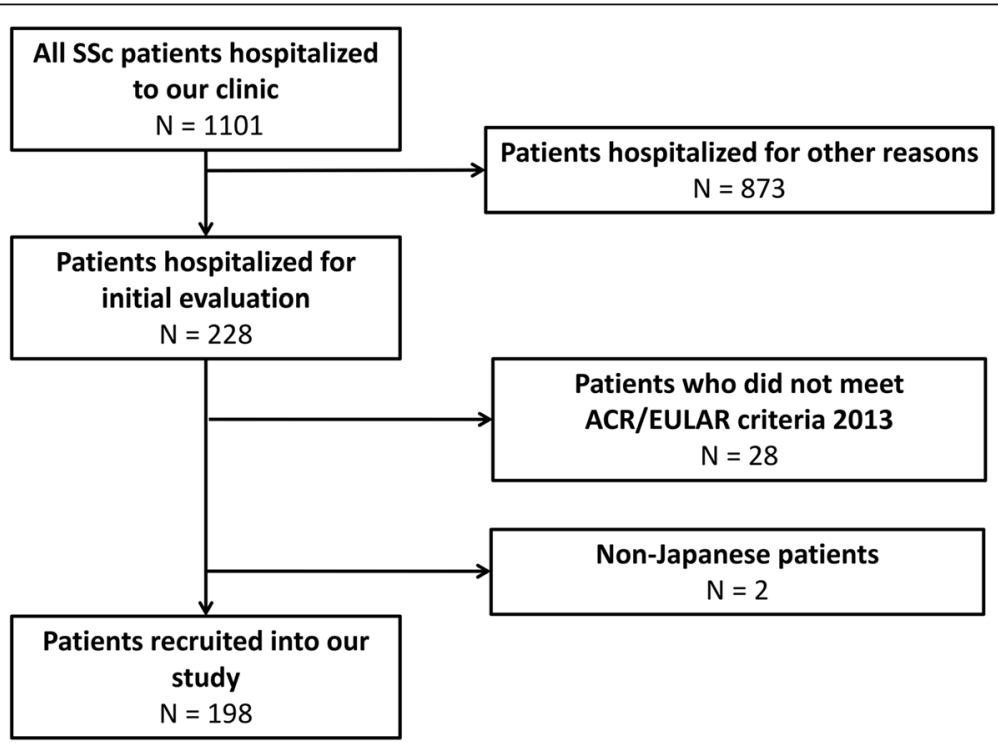

Fig. 1 The flow chart of patient recruitment. All Japanese patients with systemic sclerosis (SSc) hospitalized to our clinic for initial evaluation were collected. Patients who did not meet the classification criteria for SSc established by American College of Rheumatology and European League Against Rheumatism in 2013 (ACR/EULAR criteria 2013) were excluded. In total, 198 patients were recruited into our study 
Table 1 Clinical demographics of the subject patients

\begin{tabular}{|c|c|c|}
\hline & $N$ & $n(\%)$ or mean (SD) \\
\hline Male & 198 & $21(10.6 \%)$ \\
\hline Female & 198 & $177(89.4 \%)$ \\
\hline Age (years) & 198 & $55.4(15.5)$ \\
\hline Disease duration (years) & 196 & $7.3(8.8)$ \\
\hline Follow-up duration (years) & 198 & $3.2(2.3)$ \\
\hline History of smoking & 196 & $43(21.9 \%)$ \\
\hline Death & 198 & $4(2.0 \%)$ \\
\hline Raynaud's phenomenon & 196 & $170(86.7 \%)$ \\
\hline Puffy finger & 144 & $97(67.4 \%)$ \\
\hline Nail fold bleeding & 190 & $139(73.2 \%)$ \\
\hline Telangiectasia & 162 & $65(40.1 \%)$ \\
\hline \multicolumn{3}{|l|}{ Autoantibody } \\
\hline Anti-topo I Ab & 198 & $78(39.4 \%)$ \\
\hline Anti-centromere Ab & 198 & $64(32.3 \%)$ \\
\hline Anti-RNA polymerase III Ab & 198 & $21(10.6 \%)$ \\
\hline Anti-U1RNP Ab & 198 & $22(11.1 \%)$ \\
\hline \multicolumn{3}{|l|}{ Medications } \\
\hline Corticosteroids or immunosuppressants & 198 & $50(25.3 \%)$ \\
\hline Corticosteroids & 198 & $43(21.7 \%)$ \\
\hline Immunosuppressants & 198 & $19(9.6 \%)$ \\
\hline Vasoactive agents & 198 & $74(37.4 \%)$ \\
\hline Endothelin receptor antagonists & 198 & $14(7.1 \%)$ \\
\hline Phosphodiesterase 5 inhibitors & 198 & $5(2.5 \%)$ \\
\hline Beraprost & 198 & $52(26.3 \%)$ \\
\hline Sarpogrelate hydrochloride & 198 & $26(13.1 \%)$ \\
\hline Limaprost alfadex & 198 & $15(7.6 \%)$ \\
\hline Angiotensin-converting enzyme inhibitors & 198 & $3(1.5 \%)$ \\
\hline \multicolumn{3}{|l|}{ Others } \\
\hline Non-steroidal anti-inflammatory drugs & 198 & $27(13.6 \%)$ \\
\hline Tocopherol nicotinate & 198 & $64(32.3 \%)$ \\
\hline Proton pump inhibitors & 198 & $87(43.9 \%)$ \\
\hline \multicolumn{3}{|l|}{ Laboratory tests } \\
\hline White blood cells $\left(/ \mathrm{mm}^{3}\right)$ & 198 & $6700(2300)$ \\
\hline Hemoglobin (g/dL) & 198 & $12.3(1.9)$ \\
\hline Hematocrit (\%) & 198 & $38.5(5.1)$ \\
\hline Platelets $\left(\times 10^{4} / \mathrm{mm}^{3}\right)$ & 198 & $26.7(7.8)$ \\
\hline CRP (mg/dL) & 198 & $0.43(1.19)$ \\
\hline ESR $(\mathrm{mm} / \mathrm{h})$ & 195 & $25.8(19.7)$ \\
\hline
\end{tabular}

Skin involvement

Qualitative measurement

Diffuse cutaneous systemic sclerosis

$190 \quad 89(46.8 \%)$

Quantitative measurement

mRSS

$177 \quad 9.9(8.9)$
Table 1 Clinical demographics of the subject patients (Continued)

\begin{tabular}{lll}
\hline & $N$ & $n(\%)$ or mean (SD) \\
\hline SSc-ILD & 196 & $87(44.4 \%)$ \\
Restrictive impairment & 197 & $36(18.3 \%)$ \\
Diffusion impairment & 191 & $33(17.3 \%)$ \\
Quantitative evaluation & & \\
KL-6 (U/mL) & 198 & $519(499)$ \\
SP-D (ng/mL) & 190 & $107(98)$ \\
\%FVC (\%) & 197 & $95.9(20.8)$ \\
\%DLco (\%) & 191 & $88.3(20.0)$ \\
FEV1\% (\%) & 197 & $82.1(8.7)$
\end{tabular}

Heart involvement

Qualitative evaluation

Systolic dysfunction

$1840(0 \%)$

Diastolic dysfunction

$150 \quad 10(6.7 \%)$

Pulmonary hypertension

$198 \quad 5(2.5 \%)$

Heart failure

$1983(1.5 \%)$

Quantitative evaluation

BNP $(p g / m L)$

$191 \quad 43.0(50.0)$

LVEF (\%)

$184 \quad 70.1$ (6.3)

Ele'

$150 \quad 9.6(3.5)$

RVSP $(\mathrm{mmHg})$

$181 \quad 27.3(7.5)$

Renal involvement

Qualitative evaluation

SRC

$198 \quad 6(3.0 \%)$

Quantitative evaluation

eGFR (mL/min/1.73 m²)

$198 \quad 87.8(25.9)$

Gastrointestinal involvement

Qualitative evaluation

Reflux esophagitis

$179 \quad 78(43.6 \%)$

lleus

$198 \quad 6(3.0 \%)$

Categorical evaluation

Los Angeles classification

$\begin{array}{lll}\text { Grade N } & 179 & 101(56.4 \%) \\ \text { Grade M } & 179 & 30(16.8 \%) \\ \text { Grade A } & 179 & 32(17.9 \%) \\ \text { Grade B } & 179 & 11(6.2 \%) \\ \text { Grade C } & 179 & 4(2.2 \%) \\ \text { Grade D } & 179 & 1(0.6 \%)\end{array}$

Musculoskeletal involvement

Qualitative evaluation

$\begin{array}{ll}\text { Myositis } & 197 \quad 7(3.6 \%)\end{array}$

Quantitative evaluation

CK (U/L)

$197110(119)$

$N$ number of the observation, $n$ number of the patients applicable, $S D$ standard deviation

Lung involvement

Qualitative evaluation 
Single and multiple logistic analyses revealed that mRSS is associated with death, SRC, and lung involvement Single logistic analyses revealed that higher mRSS is related to higher incidence of death $(P<0.05)$ and SRC $(P<0.05)$. Higher mRSS was also related to baseline presence of SSc-ILD $(P<0.05)$, restrictive impairment $(P<0.01)$, and diffusion impairment $(P<0.01)$ of the lung (Table 2). Multiple logistic analyses showed that relation between mRSS and these organ involvements is statistically significant even after compensating with the patients' basic characteristics (sex, age, and disease duration). Meanwhile, no relationship was found between mRSS and incidence of ileus and heart failure. Furthermore, there was no relationship between mRSS and presence of reflux esophagitis and myositis. Collectively, higher mRSS was significantly and independently associated with higher incidence of death and SRC and higher prevalence of SSc-ILD, restrictive impairment, and diffusion impairment of the lung.

\section{Single and multiple regression analyses showed the} correlation between mRSS and lung involvement

Single regression analyses revealed that mRSS negatively correlates with \%FVC $(P<0.001)$ and \%DLco $(P<0.001)$ and positively correlates with eGFR $(P<0.05)$ and the serum level of SP-D $(P<0.05$; Table 3$)$. Correlation analyses also showed negative correlation between mRSS and \%FVC $(P<0.001$; Fig. $2 \mathrm{a})$ or \%DLco $(P<0.001$; Fig. 2b). There was no correlation between mRSS and the serum levels of KL- 6 and CK, the results of echocardiography, or endoscopic findings in the esophagus.

In addition, multiple regression analyses showed that negative correlation between mRSS and the results of pulmonary function test or serum levels of SP-D is statistically significant even after compensation with the patients' basic characteristics. In contrast, correlation between mRSS and eGFR was not statistically significant in multiple regression analyses.

\section{Sensitivity analyses clarified that correlation between $\mathrm{mRSS}$ and pulmonary function is independent from other explanatory variables}

Sensitivity analysis of the multivariate regression model was performed by adding other explanatory variables. The significance of mRSS as an explanatory variable of \%FVC and \%DLco was robust to adding baseline presence of pulmonary hypertension, the use of corticosteroids or immunosuppressants, the use of vasoactive agents, or the history of smoking (Table 4). Thus, mRSS significantly and independently correlated with \%FVC and \%DLco.

\section{Subgroup analyses revealed correlation between mRSS and lung function is significant in patients with anti-topo $\mathrm{I} A \mathrm{~b}$ and in patients with disease duration shorter than 5 years}

We performed subgroup analyses of correlation between mRSS and baseline \%FVC or \%DLco by autoantibody profile and disease duration (Table 5). In patients with

Table 2 Logistic analysis of relationship between mRSS and qualitative evaluation of organ involvement

\begin{tabular}{|c|c|c|c|c|}
\hline & \multicolumn{2}{|c|}{ Univariate analysis } & \multicolumn{2}{|c|}{ Multivariate analysis } \\
\hline & $\bar{N}$ & OR $(95 \% \mathrm{Cl})$ & $N$ & OR $(95 \% \mathrm{Cl})$ \\
\hline Death & 177 & $1.15^{*}(1.03$ to 1.29$)$ & 176 & $1.23^{*}(1.03$ to 1.46$)$ \\
\hline \multicolumn{5}{|l|}{ Lung involvement } \\
\hline Interstitial lung disease & 175 & $1.04^{*}(1.00$ to 1.08$)$ & 174 & $1.05^{*}(1.01$ to 1.09$)$ \\
\hline Restrictive impairment & 176 & $1.07^{* *}(1.03$ to 1.12$)$ & 175 & $1.07^{* *}(1.02$ to 1.12$)$ \\
\hline Diffusion impairment & 171 & $1.07^{* *}(1.02$ to 1.11$)$ & 170 & $1.06^{*}(1.01$ to 1.11$)$ \\
\hline \multicolumn{5}{|l|}{ Heart involvement } \\
\hline Diastolic dysfunction & 136 & $1.03(0.96$ to 1.10$)$ & & \\
\hline Pulmonary hypertension & 177 & 0.97 (0.86 to 1.09$)$ & & \\
\hline Heart failure & 177 & 1.11 (0.99 to 1.23$)$ & & \\
\hline \multicolumn{5}{|l|}{ Renal involvement } \\
\hline $\mathrm{SRC}$ & 177 & $1.11^{*}(1.02$ to 1.20$)$ & 176 & $1.11^{*}(1.01$ to 1.23$)$ \\
\hline \multicolumn{5}{|l|}{ Gastrointestinal involvement } \\
\hline Reflux esophagitis & 161 & 1.03 (0.99 to 1.07$)$ & & \\
\hline lleus & 177 & 1.04 (0.95 to 1.13$)$ & & \\
\hline \multicolumn{5}{|l|}{ Musculoskeletal involvement } \\
\hline Myositis & 177 & $1.03(0.95$ to 1.11$)$ & & \\
\hline
\end{tabular}

$N$ number of the observation, $O R$ odds ratio, $C l$ confidence interval. Asterisk $\left(^{*}\right)$ indicates statistical significance in logistic analysis. ${ }^{*} P<0.05 ;{ }^{*} P<0.01$ 
Table 3 Regression analysis of correlation between mRSS and quantitative or categorical evaluation of organ involvement

\begin{tabular}{|c|c|c|c|c|}
\hline & \multicolumn{2}{|c|}{ Univariate analysis } & \multicolumn{2}{|c|}{ Multivariate analysis } \\
\hline & $\bar{N}$ & $\beta(95 \% \mathrm{Cl})$ & $\bar{N}$ & $\beta(95 \% \mathrm{Cl})$ \\
\hline \multicolumn{5}{|l|}{ Lung involvement } \\
\hline $\mathrm{KL}-6$ & 177 & $5.14(-3.38$ to 13.7$)$ & & \\
\hline SP-D & 170 & $1.87^{*}(0.27$ to 3.47$)$ & 169 & $1.87^{*}$ (0.09 to 3.65$)$ \\
\hline$\% F V C$ & 176 & $-0.64^{* * *}(-0.98$ to -0.30$)$ & 175 & $-0.61^{* *}(-0.98$ to -0.23$)$ \\
\hline$\%$ DLco & 171 & $-0.67^{* * *}(-1.00$ to -0.33$)$ & 170 & $-0.53^{* *}(-0.89$ to -0.16$)$ \\
\hline \multicolumn{5}{|l|}{ Heart involvement } \\
\hline BNP & 171 & $0.82(-0.02$ to 1.66$)$ & & \\
\hline LVEF & 166 & $0.06(-0.05$ to 0.17$)$ & & \\
\hline$E / e^{\prime}$ & 136 & $0.02(-0.04$ to 0.09$)$ & & \\
\hline RVSP & 164 & $0.11(-0.02$ to 0.25$)$ & & \\
\hline \multicolumn{5}{|l|}{ Renal involvement } \\
\hline eGFR & 177 & $0.44^{*}(0.03$ to 0.85$)$ & 176 & $0.11(-0.25$ to 0.46$)$ \\
\hline \multicolumn{5}{|l|}{ Gastrointestinal involvement } \\
\hline Los Angeles classification & 161 & $0.02(-0.01$ to 0.04$)$ & & \\
\hline \multicolumn{5}{|l|}{ Musculoskeletal involvement } \\
\hline CK & 177 & $1.99(-0.09$ to 4.07$)$ & & \\
\hline
\end{tabular}

$N$ number of the observation, $\beta$ regression coefficient, $C /$ confidence interval. Asterisk (*) indicates statistical significance in regression analysis. ${ }^{*} P<0.05$; ${ }^{* *} P<0.01 ; * * P<0.001$

anti-topo I Ab, the correlation to \%FVC and \%DLco was statistically significant in both single regression analyses (\%FVC: $P<0.05$; \%DLco: $P<0.01$ ) and multiple regression analyses (\%FVC: $P<0.01$; \%DLco: $P<0.05$ ). By contrast, these correlations were not statistically significant among patients with anti-centromere, anti-RNA polymerase III, or anti-U1 RNP Abs. In addition, multivariate regression analysis showed significant correlation between mRSS and both \%FVC $(P<0.05)$ and \%DLco $(P<$ $0.05)$ in SSc patients with disease duration shorter than 5 years, while mRSS significantly correlated with \%FVC $(P<0.01)$ but not with \%DLco among patients with disease duration of 5 years or more. Taken together, correlation between mRSS and \%FVC or \%DLco was significant especially among patients with anti-topo I Ab and patients with disease duration shorter than 5 years.

\section{Longitudinal analyses showed negative correlation between the change in mRSS and that in \%FVC and \%DLco}

Longitudinal data was available for 84 patients (42.4\%). The mean follow-up duration among those patients was 2.5 years $(\mathrm{SD}=1.9)$. We examined the correlation between mRSS change $(\triangle \mathrm{mRSS})$ and pulmonary function change ( $\triangle \% \mathrm{FVC}$ and $\Delta \% \mathrm{DLco})$. Correlation analyses showed that $\triangle \mathrm{mRSS}$ negatively correlated with both $\triangle \%$ FVC $(P=0.03$; Fig. $2 \mathrm{c})$ and $\Delta \%$ DLco $(P<0.001$; Fig. 2d). Thus, the longitudinal change in mRSS negatively correlated with the longitudinal change in \%FVC and \%DLco.

\section{Discussion}

Our retrospective observation of SSc patients revealed that mRSS significantly correlates with quantitative measurements of the lung involvement such as \%FVC and \%DLco on the baseline. The correlation in multivariate regression analysis was robust to adding baseline presence of pulmonary hypertension, the use of corticosteroids or immunosuppressants, the use of vasoactive agents, and the history of smoking as explanatory variables. Moreover, the longitudinal change in mRSS significantly correlated with that in \%FVC and \%DLco. Although previous studies have shown that higher skin thickness score is related to the existence of organ involvements [15-19], correlation between skin thickness score and quantitative barometers of each organ involvement has not yet been documented in Japan. This is the first study that revealed correlation between skin thickness score and quantitative measurements of organ involvements in Japanese SSc patients.

Close relationship between skin sclerosis and lung fibrosis in SSc patients is suggested by several aspects of clinical experience. First, skin sclerosis and SSc-ILD share their chronology; they both develop in the first few years in the natural time course of SSc [27]. This corresponds to our result that correlation between skin score and pulmonary function was prominent in patients with 


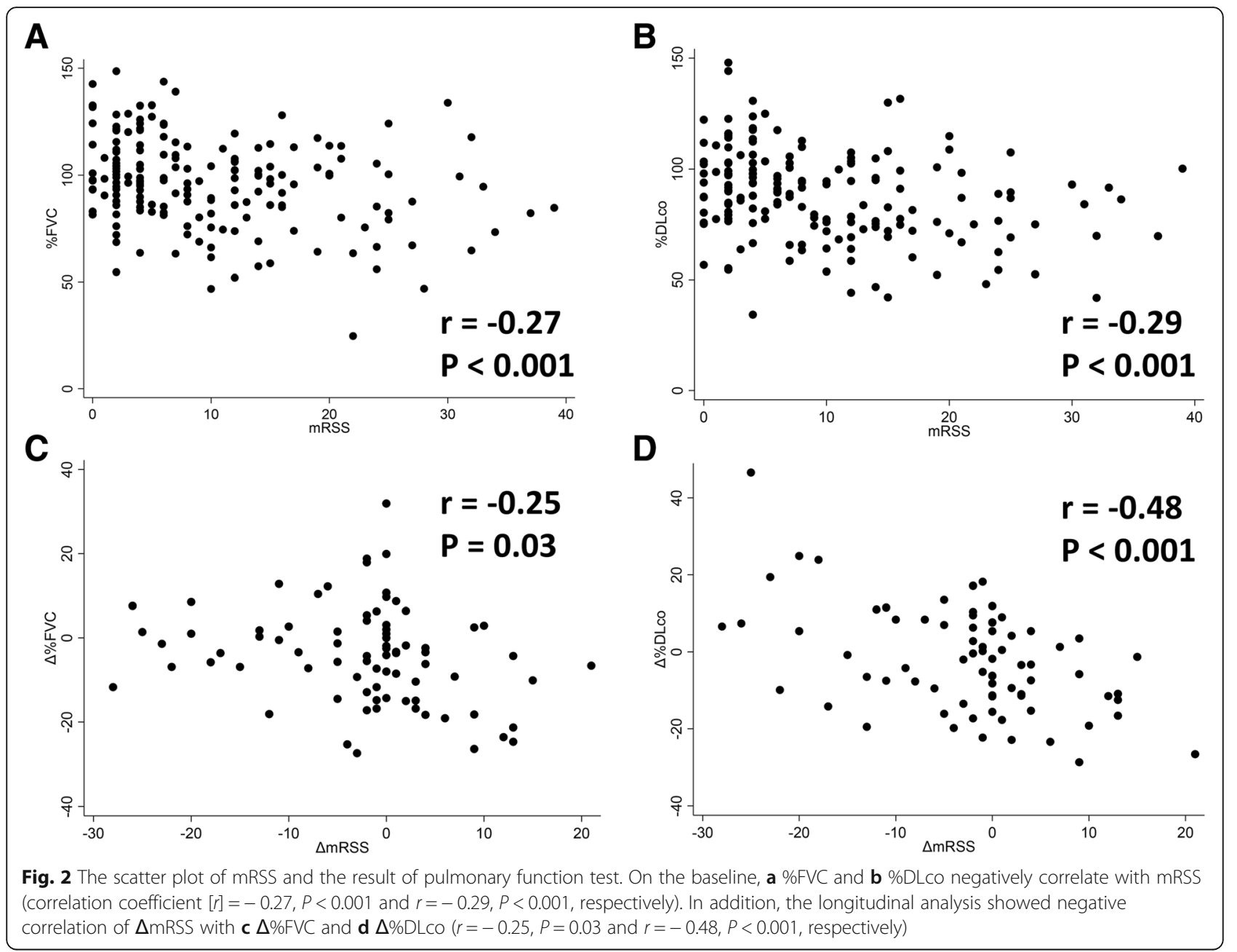

shorter disease duration. Second, pathohistological feature of skin involvement and lung involvement in SSc patients is quite similar; invasion of inflammatory cells is seen in their early stage, and proliferation and degeneration of collagen fibers is observed in their late stage [2, 3]. Third, SSc patients with anti-topo I Ab experience combination of severe skin sclerosis and SSc-ILD [7, 8]. Indeed, correlation between mRSS and pulmonary function was prominent in patients with anti-topo I Ab in our study. It suggests that skin and lung fibrosis in SSc has similar abnormality of immune system as its background. Forth, recent clinical experiences have indicated that both skin and lung fibrosis responds well to B cell-targeting therapy, including rituximab and tocilizumab. Previously, our group has revealed that B cells play a key role in the pathogenesis of SSc [28]. Abnormality of B cell function including production of autoantibodies and inflammatory cytokines, such as interleukin-6 (IL-6), contributes to the progression of fibrosis in SSc mouse models [29]. Rituximab, a chimeric monoclonal Ab binding to CD20, ablates B cells from blood circulation via targeting CD20 expressed on the

Table 4 Sensitivity analysis of the multivariate regression model

\begin{tabular}{|c|c|c|c|c|}
\hline \multirow[t]{2}{*}{ Additional variables } & \multicolumn{2}{|c|}{ \%FVC vs mRSS } & \multicolumn{2}{|c|}{$\%$ DLco vs mRSS } \\
\hline & $N$ & $\beta(95 \% \mathrm{Cl})$ & $N$ & $\beta(95 \% \mathrm{Cl})$ \\
\hline Pulmonary hypertension & 175 & $-0.59^{* *}(-0.97$ to -0.22$)$ & 170 & $-0.52^{* *}(-0.88$ to -0.16 \\
\hline Use of corticosteroids or immunosuppressants & 175 & $-0.52^{* *}(-0.89$ to -0.15$)$ & 170 & $-0.45^{*}(-0.81$ to -0.10$)$ \\
\hline Use of vasoactive agents & 175 & $-0.59^{* *}(-0.97$ to -0.22$)$ & 170 & $-0.50^{* *}(-0.85$ to -0.14 \\
\hline History of smoking & 174 & $-0.62^{* *}(-0.98$ to -0.27$)$ & 169 & $-0.52^{* *}(-0.88$ to -0.16 \\
\hline
\end{tabular}

$\beta$ regression coefficient, $\mathrm{Cl}$ confidence interval. Asterisk (*) indicates statistical significance in regression analysis.* $P<0.05 ;{ }^{* *} P<0.01$ 
Table 5 Subgroup analysis of correlation between mRSS and pulmonary function by autoantibody profile or disease duration

\begin{tabular}{|c|c|c|c|c|}
\hline & \multicolumn{2}{|c|}{ Univariate analysis } & \multicolumn{2}{|c|}{ Multivariate analysis } \\
\hline & $N$ & $\beta(95 \% \mathrm{Cl})$ & $N$ & $\beta(95 \% \mathrm{Cl})$ \\
\hline \multicolumn{5}{|l|}{$\% \mathrm{FVC}$} \\
\hline \multicolumn{5}{|l|}{ Autoantibody profile } \\
\hline Anti-topo I Ab & 65 & $-0.68^{*}(-1.25$ to -0.11$)$ & 65 & $-0.80^{* *}(-1.39$ to -0.20$)$ \\
\hline Anti-centromere Ab & 60 & $-1.36(-1.18$ to 0.91$)$ & & \\
\hline Anti-RNA polymerase III Ab & 17 & $0.66(-0.29$ to 1.61$)$ & & \\
\hline Anti-U1RNP Ab & 19 & $-0.09(-1.07$ to 0.89$)$ & & \\
\hline \multicolumn{5}{|l|}{ Disease duration } \\
\hline$<5$ years & 106 & $-0.41^{*}(-0.77$ to -0.05$)$ & 106 & $-0.43^{*}(-0.84$ to -0.02$)$ \\
\hline$\geq 5$ years & 69 & $-1.53^{* * *}(-2.36$ to -0.70$)$ & 69 & $-1.48^{* *}(-2.33$ to -0.63$)$ \\
\hline \multicolumn{5}{|l|}{$\%$ DLco } \\
\hline \multicolumn{5}{|l|}{ Autoantibody profile } \\
\hline Anti-topo I Ab & 62 & $-0.80^{* *}(-1.36$ to -0.24$)$ & 53 & $-0.68^{*}(-1.27$ to -0.08$)$ \\
\hline Anti-centromere Ab & 58 & $-0.02(-1.02$ to 1.07$)$ & & \\
\hline Anti-RNA polymerase III Ab & 17 & $-0.07(-1.03$ to 0.89$)$ & & \\
\hline Anti-U1RNP Ab & 19 & $-0.63(-1.59$ to 0.32$)$ & & \\
\hline \multicolumn{5}{|l|}{ Disease duration } \\
\hline$<5$ years & 104 & $-0.70^{* *}(-1.10$ to -0.30$)$ & 104 & $-0.52^{*}(-0.97$ to -0.07$)$ \\
\hline$\geq 5$ years & 66 & $-0.86^{*}(-1.61$ to -0.11$)$ & 66 & $-0.68(-1.43$ to 0.06$)$ \\
\hline
\end{tabular}

$N$ number of the observation, $\beta$ regression coefficient, $C l$ confidence interval. Asterisk $\left(^{*}\right)$ indicates statistical significance in regression analysis. ${ }^{*}<<0.05$;

** $P<0.01 ;{ }^{* * *} P<0.001$

surface of B cells. Some open-label clinical studies [3033] and a retrospective case-control study [34] revealed that SSc patients on rituximab showed significant improvement of mRSS and \%FVC, which is now being verified by an ongoing double-blind randomized placebo-controlled trial (UMIN000030139). Tocilizumab, a humanized monoclonal Ab binding to IL-6 receptors, inhibits the signaling pathway via IL- 6 mainly secreted by B cells that modulate inflammation and tissue fibrosis [35, 36]. A double-blind randomized placebo-controlled trial (NCT01532869) indicated that weekly subcutaneous injection of tocilizumab reduces mean mRSS and prevents FVC from decline [37, 38]. These facts highlight the crucial role of B cells in the pathogenesis of both skin and lung involvement of SSc.

Furthermore, our study showed that higher mRSS is predictive for higher mortality and higher incidence of SRC. These results from Japanese SSc cohort are consistent with those of previous studies in other ethnic populations $[18,19]$, which indicates that skin thickness may be an indicator of not only organ fibrosis represented by skin fibrosis and SSc-ILD, but also other aspects of SSc such as vasculopathy.

From a viewpoint of clinical application, mRSS is promised as a good surrogate marker of lung involvement in SSc patients. Our study showed that mRSS significantly correlates with \%FVC and \%DLco in SSc patients both on the baseline and along the time course. Other evaluation methods for SSc-ILD, including serologic marker measurements, HRCT, or 6-min walk test, are more invasive or time-consuming than measuring mRSS. Moreover, it has also been reported that mRSS is a measurement tool with less inter- and intra-observer variation [39]. Skin thickness score might be a reasonable way of monitoring the efficacy of treatments for SSc-ILD in both clinical trials and real clinical settings. Furthermore, mRSS possibly reflects the global disease activity and severity of SSc. Indeed, Composite Response Index for Systemic Sclerosis includes mRSS in its scoring [40]. Taken together, although further studies are warranted, evaluation of mRSS is useful as a surrogate marker of organ involvements, global disease activity, and severity in SSc.

The major limitation of the present study is its retrospective design. There is some missing in the data especially in longitudinal data, which may bias the result of the analyses. Moreover, the small sample size and short observation term leads to the low power of the analysis, especially for rare disease-related events or subgroup analyses. Prospective observational studies with bigger sample size and longer follow-up are desirable. In addition, the present study includes only Japanese patients. The prevalence of SSc-ILD, decreased \%DLco [41], pulmonary hypertension [42], and esophagitis [43] 
was lower than those reported in previous studies in other populations. Validation of our study should be conducted targeting other ethnicities in the future.

\section{Conclusions}

Retrospective observation of Japanese SSc patients revealed significant correlation between skin thickness and pulmonary function. Skin thickness score is a promising surrogate marker of lung involvement in systemic sclerosis.

\begin{abstract}
Abbreviations
\%DLco: Percentage of predicted diffusing capacity of the lungs for carbon monoxide; \%FVC: Percentage of predicted forced vital capacity; 95\% Cl: 95\% confidence interval; Ab: Antibody; ACR: American College of Rheumatology; BNP: Brain natriuretic peptide; CK: Creatinine kinase; CRP: C-reactive protein; Ele: Ratio between early mitral inflow velocity and mitral annular early diastolic velocity; eGFR: Estimated glomerular filtration rate; ESR: Erythrocyte sedimentation rate; EULAR: European League Against Rheumatism; FEV1\%: The ratio of forced expiratory volume in $1 \mathrm{~s}$ to forced vital capacity; GERD: Gastroesophageal reflux disease; HRCT: High-resolution computed tomography; IL-6: Interleukin-6; ILD: Interstitial lung disease; KL-6: Krebs von den Lungen-6; LVEF: Left ventricle ejection fraction; mRSS: Modified Rodnan total skin thickness score; $N$ : Number of the observation; $n$ : Number of the patients applicable; OR: Odds ratio; $r$ : Correlation coefficient; RVSP: Right ventricle systolic pressure; SD: Standard deviation; SP-D: Surfactant protein-D; SRC: Systemic sclerosis renal crisis; SSc: Systemic sclerosis; $\beta$ : Regression coefficient
\end{abstract}

\section{Acknowledgements}

None.

\section{Authors' contributions}

KMM analyzed and interpreted the patient data and was a major contributor in writing the manuscript. AY launched this study and was involved in revising the manuscript. The others participated in collecting the patient data. All authors read and approved the final manuscript.

\section{Funding}

There is no funding to declare.

\section{Availability of data and materials}

The datasets used and/or analyzed during the current study are available from the corresponding author on reasonable request.

\section{Ethics approval and consent to participate}

This study was approved by the ethics committee at The University of Tokyo Hospital. Informed consent was obtained on document from the subject patients.

\section{Consent for publication}

Not applicable.

\section{Competing interests}

The authors declare that they have no competing interests.

\section{Author details}

'Department of Dermatology, The University of Tokyo Graduate School of Medicine, 7-3-1, Hongo, Bunkyo-ku, Tokyo 1138655, Japan. ${ }^{2}$ Department of Biostatistics, School of Public Health, The University of Tokyo Graduate School of Medicine, Tokyo, Japan.

Received: 10 December 2018 Accepted: 15 May 2019

Published online: 28 May 2019

\section{References}

1. Asano Y. Systemic sclerosis. J Dermatol. 2018;45:128-38.
2. Jinnin M. Mechanisms of skin fibrosis in systemic sclerosis. J Dermatol. 2010; 37(1):11-25.

3. Arroliga AC, Podell RAM DN. Pulmonary manifestations of scleroderma. J Thorac Imaging. 1992;7(2):30-45.

4. Giuggioli D, Manfredi A, Lumetti F, Colaci M, Ferri C. Scleroderma skin ulcers definition, classification and treatment strategies our experience and review of the literature. Autoimmun Rev. 2018;17:155-64.

5. Denton CP, Lapadula G, Mouthon L, Müller-Ladner U. Renal complications and scleroderma renal crisis. Rheumatology. 2006;48:iii32-5.

6. Proudman SM, Stevens WM, Sahhar J, Celermajer D. Pulmonary arterial hypertension in systemic sclerosis: the need for early detection and treatment. Intern Med J. 2007;37:485-94.

7. Hamaguchi Y. Autoantibody profiles in systemic sclerosis: predictive value for clinical evaluation and prognosis. J Dermatol. 2010;37(1):42-53.

8. Nihtyanova SI, Denton CP. Autoantibodies as predictive tools in systemic sclerosis. Nat Rev Rheumatol. 2010;6(2):112-6.

9. Sharada B, Kumar A, Kakker R, Adya CM, Pande I, Uppal SS, et al. Intravenous dexamethasone pulse therapy in diffuse systemic sclerosis - a randomized placebo-controlled study. Rheumatol Int. 1994;14:91-4.

10. Ando K, Motojima S, Doi T, Nagaoka T, Kaneko N, Aoshima M, et al. Effect of glucocorticoid monotherapy on pulmonary function and survival in Japanese patients with scleroderma-related interstitial lung disease. Respir Investig. 2013;51:69-75.

11. Steen VD, Medsger TA, Osial TA, Ziegler GL, Alvin Shapiro BP, Rodnan GP. Factors predicting development of renal involvement progressive systemic sclerosis. Am J Med. 1984;76:779-86.

12. Helfrich DJ, Banner B, Steen VD, Medsger TA. Normotensive renal failure in systemic sclerosis. Arthritis Rheum. 1989;32(9):1128-34.

13. Thompson AE, Shea B, Welch V, Fenlon D, Pope JE. Calcium-channel blockers for Raynaud's phenomenon in systemic sclerosis. Arthritis Rheum. 2001:44(8):1841-7.

14. Konrad-Dalhoff I, Baunack AR, Rämsch KD, Ahr G, Kraft H, Schmitz H, et al. Effect of the calcium antagonists nifedipine, nitrendipine, nimodipine and nisoldipine on oesophageal motility in man. Eur J Clin Pharmacol. 1991;41: 313-6.

15. Clements PJ, Lachenbruch PA, Ng SC, Simmons M, Sterz M, Furst DE. Skin score: a semiquantitative measure of cutaneous involvement that improves prediction of prognosis in systemic sclerosis. Arthritis Rheum. 1990;33(8): 1256-63.

16. Clements PJ, Hurwitz EL, Wong WK, Seibold JR, Mayes M, White B, et al. Skin thickness score as a predictor and correlate of outcome in systemic sclerosis: high-dose versus low-dose penicillamine trial. Arthritis Rheum. 2000;45(11):2445-54

17. Wiese AB, Berrocal VJ, Furst DE, Seibold JR, Merkel PA, Mayes MD, et al. Correlates and responsiveness to change of measures of skin and musculoskeletal disease in early diffuse systemic sclerosis. Arthritis Care Res. 2014;66(11):1731-9.

18. Amjadi S, Maranian P, Furst DE, Clements PJ, Weng KW, Postlethwaite AE, et al. Course of the modified Rodnan skin thickness score in systemic sclerosis clinical trials: analysis of three large multicenter, double-blind, randomized controlled trials. Arthritis Rheum. 2009;60(8):2490-8.

19. Shand L, Lunt M, Nihtyanova S, Hoseini M, Silman A, Black CM, et al. Relationship between change in skin score and disease outcome in diffuse cutaneous systemic sclerosis: application of a latent linear trajectory model. Arthritis Rheum. 2007;56(7):2422-31.

20. Clements PJ, Wong WK, Hurwitz EL, Furst DE, Mayes M, White B, et al. The disability index of the health assessment questionnaire is a predictor and correlate of outcome in the high-dose versus low-dose penicillamine in systemic sclerosis trial. Arthritis Rheum. 2001;44(3):653-61.

21. Clements PJ, Wong K, Hurwitz EL, Furst DE, Mayes M, White B, et al. Correlates of the disability index of the health assessment questionnaire: a measure of functional impairment in systemic sclerosis. Arthritis Rheum. 1999;42(11):2372-80.

22. Domsic RT, Rodriguez-Reyna T, Lucas M, Fertig N, Medsger TA. Skin thickness progression rate: a predictor of mortality and early internal organ involvement in diffuse scleroderma. Ann Rheum Dis. 2011;70:104-9.

23. Khanna D, Furst DE, Clements PJ, Allanore Y, Baron M, Czirjak L, et al. Standardization of the modified Rodnan skin score for use in clinical trials of systemic sclerosis. J Scleroderma Relat Disord. 2017;2(1):11-8.

24. Van Den Hoogen F, Khanna D, Fransen J, Johnson SR, Baron M, Tyndall A, et al. 2013 classification criteria for systemic sclerosis: an American College 
of Rheumatology/European League against rheumatism collaborative initiative. Arthritis Rheum. 2013;65(11):2737-47.

25. Armstrong D, Bennett JR, Blum AL, Dent J, De Dombal FT, Galmiche P, et al. The endoscopic assessment of esophagitis: a progress report on observer agreement. Gastroenterology. 1996;111:85-92.

26. Czirjak L, Nagy Z, Aringer M, Riemekasten G, Matucci-cerinic M, Furst DE. The EUSTAR model for teaching and implementing the modified Rodnan skin score in systemic sclerosis. Ann Rhem Dis. 2007;66:966-9.

27. Steen VD, Medsger TA. Severe organ involvement in systemic sclerosis with diffuse scleroderma. Arthritis Rheum. 2000;43(11):2437-44.

28. Yoshizaki A, Sato S. Abnormal B lymphocyte activation and function in systemic sclerosis. Ann Dermatol. 2015;27(1):1-9.

29. Hasegawa M, Hamaguchi Y, Yanaba K, Bouaziz JD, Uchida J, Fujimoto M, et al. B-lymphocyte depletion reduces skin fibrosis and autoimmunity in the tight-skin mouse model for systemic sclerosis. Am J Pathol. 2006;169(3):954-66.

30. Smith V, Van Praet JT, Vandooren B, Van Der Cruyssen B, Naeyaert JM, Decuman $S$, et al. Rituximab in diffuse cutaneous systemic sclerosis: an open-label clinical and histopathological study. Ann Rheum Dis. 2010;69(1): 193-7.

31. Daoussis D, Liossis S-NC, Tsamandas AC, Kalogeropoulou C, Kazantzi A Sirinian C, et al. Experience with rituximab in scleroderma: results from a 1-year, proof-of-principle study. Rhematology (Oxford). 2010;49:271-80

32. Daoussis D, Liossis S-NC, Tsamandas Christina Kalogeropoulou AC, Paliogianni F, Sirinian C, Yiannopoulos G, et al. Effect of long-term treatment with rituximab on pulmonary function and skin fibrosis in patients with diffuse systemic sclerosis. Clin Exp Rheumatol. 2012:30:17-22.

33. Daoussis D, Melissaropoulos K, Sakellaropoulos G, Antonopoulos I, Markatseli TE, Simopoulou T, et al. A multicenter, open-label, comparative study of B-cell depletion therapy with rituximab for systemic sclerosis-associated interstitial lung disease. Semin Arthritis Rheum. 2017 Apr;46(5):625-31.

34. Jordan S, Distler JHW, Maurer B, Huscher D, Van Laar JM, Allanore Y, et al. Effects and safety of rituximab in systemic sclerosis: an analysis from the European Scleroderma Trial and Research (EUSTAR) group. Ann Rheum Dis. 2015;74(6):1188-94.

35. Snir A, Kessel A, Haj T, Rosner I, Slobodin G, Toubi E, et al. Anti-IL-6 receptor antibody (tocilizumab): a B cell targeting therapy. Ecp Rheumatol. 2011;29: 697-700.

36. Roll $P$, Muhammad K, Schumann $M$, Kleinert $S$, Einsele $H$, Dörner T, et al. In vivo effects of the anti-interleukin- 6 receptor inhibitor tocilizumab on the $B$ cell compartment. Arthritis Rheum. 2011;2011(63):1255-64.

37. Khanna D, Denton $C P$, Jahreis $A$, van Laar JM, Frech TM, Anderson ME, et al. Safety and efficacy of subcutaneous tocilizumab in adults with systemic sclerosis (faSScinate): a phase 2, randomised, controlled trial. Lancet. 2016; 387:2630-40.

38. Khanna $\mathrm{D}$, Denton CP, Lin CJF, Van Laar JM, Frech TM, Anderson ME, et al. Safety and efficacy of subcutaneous tocilizumab in systemic sclerosis: results from the open-label period of a phase II randomised controlled trial (faSScinate). Ann Rheum Dis. 2018:77(2):212-20.

39. Clements P, Lachenbruch P, Siebold J, White B, Weiner S, Martin R, Weinstein A, Weisman M, Mayes MCD. Inter and intraobserver variability of total skin thickness score (modified Rodnan TSS) in systemic sclerosis. J Rheumatol. 1995;22:1281-5.

40. Khanna D, Berrocal VJ, Giannini EH, Seibold JR, Merkel PA, Mayes MD, et al. The American College of Rheumatology provisional composite response index for clinical trials in early diffuse cutaneous systemic sclerosis. Arthritis Care Res. 2016;68(2):167-78.

41. Suliman YA, Dobrota R, Huscher D, Nguyen-Kim TDL, Maurer B, Jordan S, et al. Pulmonary function tests: high rate of false-negative results in the early detection and screening of scleroderma-related interstitial lung disease. Arthritis Rheumatol. 2015;67(12):3256-61.

42. Hachulla E, Gressin V, Guillevin L, Carpentier P, Diot E, Sibilia J, et al. Early detection of pulmonary arterial hypertension in systemic sclerosis: a French nationwide prospective multicenter study. Arthritis Rheum. 2005;52(12): 3792-800.

43. Akesson BYA, Wollheim FA. Organ manifestations in 100 patients with progressive systemic sclerosis: a comparison between the CREST syndrome and diffuse scleroderma. Br J Rheumatol. 1989;28(4):281-6.

\section{Publisher's Note}

Springer Nature remains neutral with regard to jurisdictional claims in published maps and institutional affiliations.

\section{Ready to submit your research? Choose BMC and benefit from}

- fast, convenient online submission

- thorough peer review by experienced researchers in your field

- rapid publication on acceptance

- support for research data, including large and complex data types

- gold Open Access which fosters wider collaboration and increased citations

- maximum visibility for your research: over $100 \mathrm{M}$ website views per year

At BMC, research is always in progress.

Learn more biomedcentral.com/submissions 